\title{
Anatomical Variation of the Brachial Plexus: An Ancillary Nerve of the Middle Trunk Communicating with the Radix of the Median Nerve
}

\author{
Minh Huynh ${ }^{1}$, Stewart Spence ${ }^{1}$, Johnny W. Huang ${ }^{1}$ \\ ${ }^{1}$ Faculty of Medicine, University of Ottawa
}

ABSTRACT

Purpose: Variations in brachial plexus anatomy are common. As such, the knowledge of variations is essential for surgeons and anesthesiologists to decrease the risk of iatrogenic injuries. Moreover, brachial plexus variations often co-exist with aberrant vasculature. The median nerve is formed from contributions by the lateral and medial cords. This case report details a unique variant in the formation of the median nerve.

Methods: The anatomical variant presented was identified during an upper-limb dissection of an adult cadaver.

Results: The anatomical variant presented demonstrates a bifurcation of the middle trunk of the brachial plexus that coalesces to the radix of the median nerve. Although prior studies have demonstrated median nerve brachial plexus variations, the aforementioned variant arises directly from the middle trunk and communicates directly with the median nerve, while previously mentioned variants often connect to the medial or lateral cords.

Conclusion: The communicating branch between the anterior division of the middle trunk and radix of the median nerve represents a unique and uncommon anatomical variation.

\section{RÉSUMÉ}

Objectif: Les variations de l'anatomie du plexus brachial sont fréquentes. En tant que tel, la connaissance des variations est essentielle pour les chirurgiens et les anesthésiologistes afin de diminuer le risque de lésions iatrogènes. De plus, les variations du plexus brachial coexistent souvent avec un système vasculaire aberrant. Le nerf médian est formé de contributions par les cordes latérales et médiales. Ce rapport de cas détaille une variante unique dans la formation du nerf médian.

Méthodes: La variante anatomique présentée a été identifiée lors d'une dissection d'un cadavre chez un adulte.

Résultats: La variante anatomique présentée montre une bifurcation du tronc médian du plexus brachial qui coalesce avec la base du nerf médian. Bien que des études antérieures aient démontré des variations médianes du plexus brachial, la variante susmentionnée provient directement du tronc central et communique directement avec le nerf médian, alors que les variantes mentionnées précédemment se connectent souvent aux cordons médiaux ou latéraux.

Conclusion: La branche communicante entre la division antérieure du tronc central et la base du nerf médian représente une variation anatomique unique et peu commune.

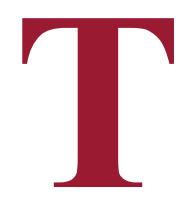

he brachial plexus is formed by contributions from the anterior rami of spinal nerves C5-T1. Spinal nerves $\mathrm{C} 5$-C6 continue to form the superior trunk; C7 continues to form the middle trunk, and C8-T1 forms the inferior trunk. Each trunk then divides into anterior and posterior divisions. The anterior divisions of the superior and middle trunk form the lateral cord, while the anterior division of the inferior trunk forms the medial cord. Finally, the lateral cord and the medial cord unite to form the median nerve proper (Figure 1) (1).
Studies by Miller et al elucidate the origins of the brachial plexus The brachial plexus is a pervasive structure apparent since the existence of amphibians. The structure began as no more than several nerve segments in amphibians that progressed and differentiated into its current intricate and complex state (2-5). The evolution of the brachial plexus can be attributed to the diversification of the corresponding blood supply and musculature. The orientation of the axillary artery is responsible for the intrinsic variation, meanwhile the foundation of the brachial plexus is dependent on the musculature. For instance, the branching

Keywords: Brachial plexus; Variation; Anatomy; Median nerve; Middle trunk; Cadaver 


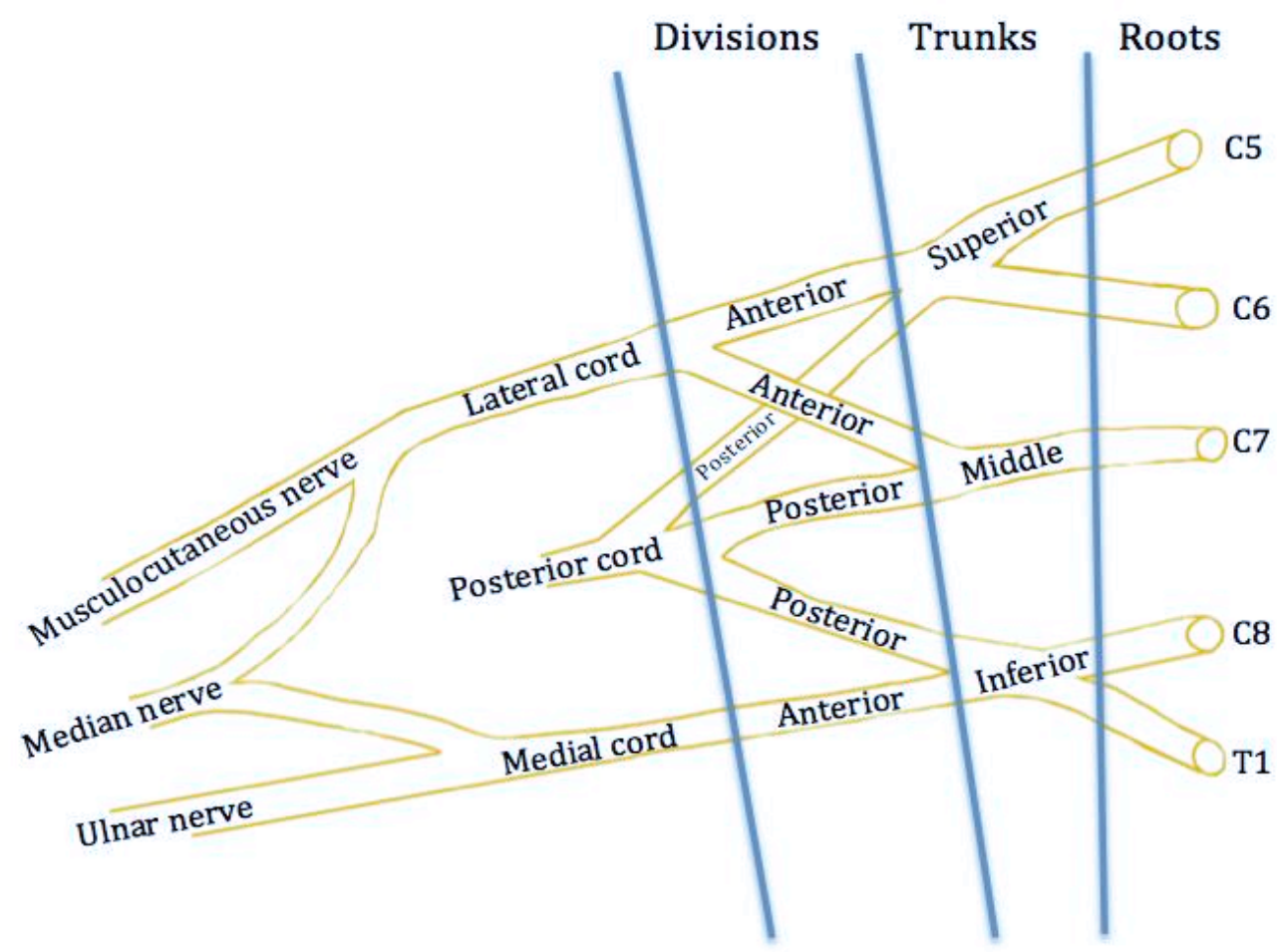

Figure 1. Illustration demonstrating normal brachial plexus anatomy.

pattern of the musculocutaneous nerve is dictated by the muscle it innervates. In primitive species, such as the lemuroids, the coracobrachialis muscle contains three heads. Consequently, their brachial plexus contains additional nerve branches superior to the musculocutaneous nerve from the lateral cord. These additional nerve fibres are not found in higher-level species. In apes, the coracobrachialis and biceps are almost completely fused, thus, these nerve fibres have completely regressed $(4,5)$. Normally, the development of the brachial plexus in humans starts at the 34th to 35th day of intrauterine life and proceeds to the definitive adult pattern by the 46th to 48th day (2-5). Any alteration in the signaling between mesenchymal cells and neuronal growth cones can lead to significant brachial plexus variations (1-3).

\section{METHODS AND RESULTS}

The anatomical variant presented was identified during routine upper-limb dissection of an adult cadaver through the Faculty of Medicine, Ottawa, Ontario. Upon dissection, anatomical variations of the brachial plexus were carefully noted. The anatomical variant presented demonstrates a bifurcation of the middle trunk of the brachial plexus that coalesces to the radix of the median nerve. Permission to take the photo in this article was granted by the University of Ottawa Faculty of Medicine by the Department of Anatomy.

\section{DISCUSSION}

\section{Previous Descriptions of Similar Variants}

Common aberrations in the structure of the brachial plexus have a tendency to share vestigial features of more primitive species. For example, in humans, the correct anatomical orientation of the axillary artery is deep to the plexus. Conversely, the majority of primitive species have their artery superficial to the nerves and represent one of the most common human variations. Therefore, brachial plexus variations are due to errors during the embryological developmental process and are often remnants of vestigial structures $(4,5)$. The purpose of this case report is to detail a unique variant in the formation of the median nerve.

Several anatomical median nerve variants have been previously reported. For example, in a study of 130 brachial plexus variants in 1999, Uzun and Bilgic found that 14 of 130 brachial plexuses (10.80\%) demonstrated "a connection between the medial radix of the medial nerve and ventral division of the middle trunk." 


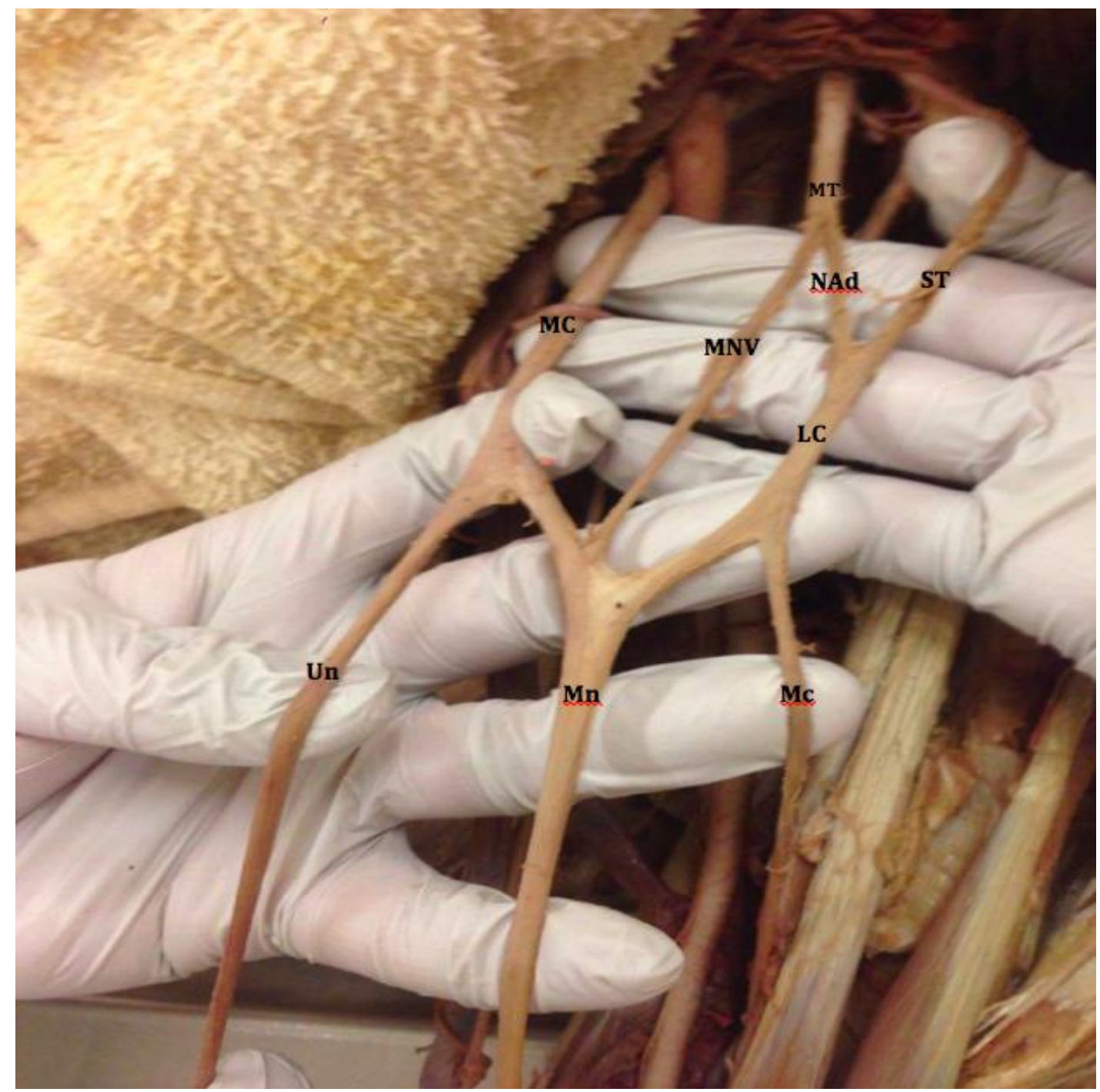

Figure 2. Median nerve variant demonstrating additional ancillary branch (MNV) arising from the middle trunk (MT) and uniting to form the median nerve (Mn) at the union of the lateral (LC) and medial cords (MC) of the median nerve. Abbreviations: Ulnar nerve (Un), median nerve (Mn), musculocutaneous nerve (Mc), medial cord (MC), lateral cord (LC), median variant (MNV), normal anterior division (NAd), superior trunk (ST), middle trunk (MT).

Additionally, 2 of 130 plexuses contained a contribution from the posterior division of the middle trunk connecting to the medial cord (6). In 2006, Goyal and colleagues reported a bilateral cadaveric anomaly. On the right side, the median nerve was formed by the lateral and medial cords with a supplementary branch from the lateral cord. The proximal aspect of the lateral cord gave rise to a small communicating branch, which eventually joined the median nerve. In the left axilla the median nerve was formed by a similar, but more complex union of two lateral cord roots and one medial cord root. The anomalous proximal contribution of the lateral cord diverged from the an- terior division of the middle trunk and lateral cord proper and provided an additional small communicating branch that traveled medially to reach the medial cord. Finally, the distal contribution of the lateral cord united with the medial cord normally to form the median nerve proper (7). More recently, Padur and colleagues, studying lateral cord variations in 82 cadaveric brachial plexuses, demonstrated 6 anomalies. Notably, in one limb the median nerve was formed by three roots; two of the roots arose directly from the medial side of the lateral cord, and the last root arose from medial cord. The three roots joined to form the trunk of the median nerve, and encircled the axillary artery 
(8).

\section{Discussion of Variant and Clinical Implications}

Most commonly, reported median nerve variants demonstrate either a) additional roots arising from the lateral or medial cords uniting to form the median nerve; or b) roots diverging from the middle trunk to join the lateral or medial cords. The anatomical variant presented, however, demonstrates an uncommon additional anterior division arising directly from the middle trunk and uniting to form the median nerve at the union of the lateral and medial cords of the median nerve (Figure 2).

Although the anatomical variation presented may not have impacted limb function directly, variations in brachial plexus anatomy may have clinical significance for surgical and anesthesiological operations performed around the brachial plexus and its vasculature (e.g., neck surgeries). Moreover, previously reported data suggests that brachial plexus and median nerve variations correlate with variations in the anatomy of the axillary artery (9). For example, Singhal et al, reporting several anomalous cord variations in a single cadaveric brachial plexus, identified an abnormal relationship of the median nerve to the axillary artery, such that "the median nerve lay medial to the axillary artery" (9). Current anesthesiological methods for assessment of brachial plexus anatomy prior to surgical operation include: 1) blind approach; 2) peripheral nerve stimulation囚whereby a nerve is stimulated to produce paresthesia; and 3) ultrasound guidance. The first and second methods generally increase the risk of complications if aberrant anatomy exists, whereas ultrasound guidance renders a lower potential risk of operational complications, given the increased rate of detection of anatomical abnormalities. As demonstrated in this case, the potential for anatomical and vascular variations to exist is not uncommon. This emphasizes the need for thorough preoperative evaluation of brachial plexus anatomy, including ultrasound guidance, in order to detect anatomical variations, and decrease the rate of complications (10).

\section{REFERENCES}

1. Williams PL, Bannister LH, Berry MM, et al. Nervous system. In: Gray's anatomy, 38th ed. New York: Churchill Livingstone; 1992. 1266- 1272 p.

2. Moore KL, Persaud TVN. The Developing Human: clinically oriented embryology. 10th ed. Philadelphia, PA: Saunders/Elsevier; 2004. 10 p.

3. Sannes HD, Reh T, Harris W. Development of nervous system. In: Axon Growth Guidance. New York: Academic press; 2000. 189-197 p.

4. Miller RA. Comparative studies upon the morphology and distribution of brachial plexus. Am J Anat. 1934;54(1):143-7.

5. Miller RA. Observations upon the arrangement of the axillary artery and brachial plexus. Am J Anat. 1939;64(1):143-3.

6. Uzun A. Some Variations in the Formation of the Brachial Plexus in Infants.
Turk J Med Sci. 1999;29(5):573-8.

7. Goyal N Harjeet, Gupta M. Bilateral variant contributions in the formation of median nerve. Surg Radiol Anat. 2005;27(6):562-5.

8. Padur AA, Kumar N, Shanthakumar SR, Shetty SD, Prabhu GS, Patil J. Unusual and Unique Variant Branches of Lateral Cord of Brachial Plexus and its Clinical Implications - A Cadaveric Study. J Clin Diagn Res. 2016;10(4):AC01-AC04.

9. Singhal $S$, Rao VV, Ravindranath R. Variations in brachial plexus and the relationship of median nerve with the axillary artery: a case report. J Brachial Plex Peripher Nerve Inj. 2007;2:21.

10. Macfarlane A, Brull R. Ultrasound Guided Supraclavicular Block. Journal of New York School of Regional Anesthesia. 2009;12:6-10. 